\title{
The Acoustical Performance of Water Hyacinth Based Porous-Ceramic Compared to the Biomass Fiber Composites for Architecture Application
}

\author{
Erni Setyowati ${ }^{1, *}$, Gagoek Hardiman ${ }^{1}$, Nur Farida Grafiana ${ }^{2}$ \\ ${ }^{1}$ Department of Architecture, Faculty of Engineering, Diponegoro University, Semarang, 50275, Indonesia \\ ${ }^{2}$ Department of Chemistry, Faculty of Science and Mathematics, Diponegoro University, Semarang, 50275, Indonesia
}

Received November 21, 2020; Revised January 7, 2021; Accepted January 28, 2021

\section{Cite This Paper in the following Citation Styles}

(a): [1] Erni Setyowati, Gagoek Hardiman, Nur Farida Grafiana, "The Acoustical Performance of Water Hyacinth Based Porous-Ceramic Compared to the Biomass Fiber Composites for Architecture Application," Civil Engineering and Architecture, Vol. 9, No. 1, pp. 139-149, 2021. DOI: 10.13189/cea.2021.090112.

(b): Erni Setyowati, Gagoek Hardiman, Nur Farida Grafiana (2021). The Acoustical Performance of Water Hyacinth Based Porous-Ceramic Compared to the Biomass Fiber Composites for Architecture Application. Civil Engineering and Architecture, 9(1), 139-149. DOI: 10.13189/cea.2021.090112.

Copyright $(2021$ by authors, all rights reserved. Authors agree that this article remains permanently open access under the terms of the Creative Commons Attribution License 4.0 International License

\begin{abstract}
The hyacinth plant (Eichhornia crassipes) is an aquatic weed that causes the silting of swamps. The water hyacinth research was developed because of concerns over the threat of biodiversity in swamps by utilizing water hyacinth for ceramic and composite mixtures. This current research highlights the comparative acoustical performances of ceramic and composite with water hyacinth contents. Dried water hyacinth was added to the clay ceramic mixture with a weight percentage of 2 , 6,8 , and $10 \mathrm{wt} \%$. The ceramic dough was then shaped hexagonally with an interlock system and molded overlay respectively before burning and biscuits, while the composite dough consisted of $200 \mathrm{ml}$ polyester resin: 25 $\mathrm{mg}$ water hyacinth: $20 \mathrm{ml}$ catalyst. The acoustic test methods refer to ASTM 1050-98 and ASTM E2611-09 for sound absorption and sound transmission loss respectively. The result showed that the $8 \mathrm{wt} \%$ water hyacinth mixture of porous ceramic had an average absorption coefficient of 0.29 and a sound transmission loss of a wide range of frequencies with an average of $59.1 \mathrm{~dB}$. Meanwhile, the resin composite has a poor average of sound absorption of $0.10-0.11$ and $58.08-58.36 \mathrm{~dB}$ on its STL. The innovation of the water hyacinth-ceramic, however, had a promising character as a Helmholtz-based diffuser-absorber.
\end{abstract}

Keywords Eichhornia crassipes, Swamp Sedimentation, Porous Ceramics, Diffuser Absorber

\section{Introduction}

The water hyacinth (Eichhornia crassipes) is an aquatic weed that damages swampy environments. In 8 months, ten Eichhornia crassipes will grow rapidly to 600,000 . This causes the swamp environment to experience sedimentation and disturbs the swamp ecosystem. Small industries in Lopait village, Semarang district, Central Java Province Indonesia, use water hyacinths for various creative crafts to reduce the growth rate of water hyacinths and the deterioration of the quality of the swamp environment. During its development, Eichhornia crassipes is dried and powdered. This research not only focuses on porous hexagonal ceramic innovation by using water hyacinth powder in clay mixtures, in that it has the ability of absorption and material insulation but also compares the acoustic performance of porous ceramic with water hyacinth-based composites obtained in previous studies[1]. Meanwhile, several studies on acoustic materials from natural materials have also been carried out[2], [3].

Several studies have investigated hexagonal or honeycomb-shaped materials, porous ceramic, and waste-based materials that deserve appreciation because they support the concept of sustainability[4]. The study by Tang et al. investigated the honeycomb sandwich panel as an absorber[5]. In the research, they optimized the design of the sandwich structure based on the role of small 
perforated in the top face sheet and corrugation in the sandwich on improving sound absorption in the low frequencies. However, in their conclusion, it was found that the perforated face sheet was quite better on the mechanical property rather than the corrugated shape. Unlike Tang's study, the research performed by Yu et al. created square honeycomb sandwich panels on two different types based on the differences of the web-panel thickness and the dimension of the honeycomb cell. The structural design of the sandwich panel shape is approached by simulating the Finite Element (FE)[6]. Finite element results reveal that ribs placed next to its symmetrical plane are more sensitive to changes in thickness or location than ribs placed adjacent to the clamped edge. Those studies are very comprehensive in terms of design and material performance; however, none of the studies have the uniqueness of being associated with an interlocked system and a role as a bottleneck shape-based Helmholtz resonator with Eichhornia crassipes (water hyacinth). This study discusses an innovative new material made of clay ceramic mixed with water hyacinth powder which has reliable acoustic performance and compares it with the results of previous studies on water hyacinth-based composites.

Most of the porous absorbers have a lack of durability due to the fibrous material that molds easily, gets damp due to weather, and is prone to damage. Several studies have tried to create a porous material as an absorber. Several studies investigated water hyacinth as a potential natural fiber which was being explored as useful materials for various applications. Having observed the water hyacinth fiber on its thermal performance[7], Bhuvaneshwari and Sangeeta investigated the physical, structural, and mechanical properties of water hyacinth mixed with hemp for non-woven textiles. The research reveals that the WH fiber has decent strength at 220.5 $\mathrm{g} / \mathrm{tex}$ and they mixed it with hemp fiber in three ratios[8]. They concluded in the final step that the more proportion of WH caused the more the thermal resistivity (especially for the sample of WH75/H25) and the less the density of the fabric. On the other hand, Cayanan et al.'s research observed the water hyacinth differently when they compared it with other fibers, abaca, and bamboo[9]. The water hyacinth was extracted, pretreated, and blended with polyester; and after that, they carded and needle-punched it before testing its sound absorption performance. They claimed that the WH-based material had 0.82 at $6,300 \mathrm{~Hz}$, and there was no interlocked system on their materials. Further research was initiated by Subpa-Asa et al. when they mixed the water hyacinth into a concrete material to become lightweight concrete[10]. In this research, the water hyacinth replaced sand as a component on lightweight concrete in various fractions, $0 \%, 2.5 \%, 5 \%, 7.5 \%$, and $10 \%$. The best performance occurred in a $5 \%$ fraction of water hyacinth when it tested on its density and compressive strength. Although it did not observe the acoustical performance, they performed water hyacinth innovation on concrete materials. Such studies have got some knowledge about water hyacinth discoveries, but none of them learned how water hyacinth was engaged in ceramic as acoustical-Helmholtz performance. Therefore, this research creates porous ceramic material and composite made of natural fiber, which has high durability and has never been conducted by other researchers all over the world before. Although hard materials will have the most reflective properties, the idea of adding a resonator and water hyacinth content in ceramic as well as natural fiber-based composite will improve the insulation and absorption performance of the material.

\subsection{Water Hyacinth as Waterweed in Swamp Areas}

Water hyacinth (Eichhornia crassipes) is an aquatic weed, the growth of which is difficult to control. This plant can reproduce from 10 stems to 600,000 stems in 8 months. Therefore, in one month, one water hyacinth plant will grow to 7,500 stems. The very rapid growth of water hyacinths destroyed the swampy ecosystem in rural areas. By silting the swampy area, the surrounding rice fields will experience a decrease in water discharge; consequently, it affects the growth of rice plants, which are the staple food of the Indonesian. Such a decline in environmental quality must be resolved with real steps related to some efforts to significantly inhibit the growth of water hyacinths. One such effort is the use of water hyacinths as handicrafts, interior furniture, household items such as food covers, and many more. The idea of this research was started from the addition of water hyacinth flour fiber to the clay ceramic dough. It aims to create a porous ceramic that can absorb sound and noise. Several studies on the use of water hyacinth have been carried out by several researchers. To illustrate, Bagir and Pradana created a water hyacinth composite and observed its performance of tensile strength, flexural strength, water content, water absorption, and thick expansion[11]. Other studies are concerned with the threat of biodiversity in swamp life due to water hyacinth plants which cause the closed surface of swamp water, the reduced oxygen for fish habitat, and the silting of swamps. Bhuvaneswari et al. processed water hyacinth with hemp to become textile material[8]. Cayanan et al. made materials from water hyacinth and polyester[9]. They watch for sound absorption performance. Meanwhile, Subpa-Asa et al. process concrete-based water hyacinth material which has a good performance on its compressive strength[10]. The current research has specialties in terms of creating the porous ceramic with resonators, having the Helmholtz resonator concept, and having the interlocked system, so it is easy to be fitted in interior applications.

\subsection{The Role of Water Hyacinth in Acoustical Materials}

The $15 \mathrm{~mm}$ and $30 \mathrm{~mm}$ thickness of water hyacinth 
composite were compared to the same thicknesses of the coco-husk composite in a study led by Setyowati et al.[1]. The usual treatment covering additional resonators, air gap, and the fibrous layer was applied to the specimens to improve the acoustical performances of biomass fiber-based materials. The results showed that originally the acoustical performance of both specimens is not very different. However, after four resonators were added to the specimens, the acoustic difference started to show. Finally, after the 8 resonators and fibrous layers were added, the sound absorption performances significantly occurred. The sound absorption performance of coco-husk reached the wideband frequencies, while the water hyacinth-based composite did not.

Research administered by Punitha et, al created water hyacinth-based material as they were concerned with swamp sedimentation which threatened its biodiversity because of water hyacinth growth[8]. In their study, Punitha et al. made several ways of creating the material with different additional substances mixed with water hyacinth and observed their behavior in sound absorption. As the water hyacinth content was mixed with sodium hydroxide and soap solution, the conclusion was made that the water hyacinth had absorption performance as much as 5 to 10 times their weight. Therefore, this chemical processed material can be considered as absorbance in various applications.

\section{Materials and Methods}

Porous acoustic materials made from natural fibers have been widely discussed by scientists. Most of the materials are brittle, flammable, and moldy; however, porous performance may absorb the sound energy quite well. The lower the material density is the better the sound absorption performance. Research by Setyowati et al. revealed that water hyacinth-based composite with polyester resin JUSTUS 2522 has a composition of natural fiber: polyester resin: catalyst as $25 \mathrm{~g}: 200 \mathrm{ml}: 20$ $\mathrm{ml}$. Meanwhile, in this current research, the porous ceramic was made of clay batter added with water hyacinth in various $\mathrm{wt} \%$.

The clay batter consisted of formulation of clay $30 \%$, quartz $20 \%$, kaolin $10 \%$, felspar $15 \%$, minor ingredients in the form of $10 \%$ hardener, water hyacinth fiber in various percentages, $10 \mathrm{wt} \%, 8 \mathrm{wt} \%, 4 \mathrm{wt} \%, 2 \mathrm{wt} \%$, and the rest is water. The ceramic molding process goes through several processes covering pouring slurry, burning process, and biscuits.

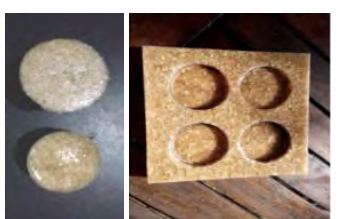

(a) (b)

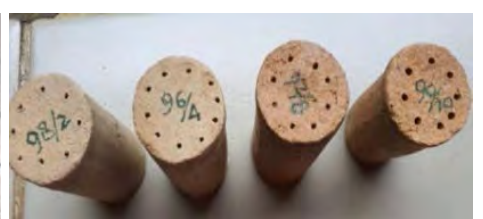

(c)
Figure 1. (a) The samples of water hyacinth composite; (b) the Architectural material made of water hyacinth composite; (c) the samples of porous ceramics

The material tests were pursued based on the ASTM 1050-98 and ASTM E2611-09 for sound absorption and Sound Transmission Loss performances respectively. Before the acoustical performances were measured, the density of the specimens was investigated (see Fig.1). Table 1 describes the results of material density. Then the further subheadings are the acoustical test procedures covering absorption coefficient and sound transmission loss procedures respectively.

Table 1. The Density of the materials

\begin{tabular}{|c|c|c|c|c|c|c|}
\hline Code & $\begin{array}{l}\text { Clay } \\
(\%)\end{array}$ & $\begin{array}{l}\text { WH } \\
(\%)\end{array}$ & $\begin{array}{l}\text { Diameter } \\
(\mathrm{mm})\end{array}$ & $\begin{array}{l}\text { Volume } \\
\left(\mathrm{cm}^{3}\right)\end{array}$ & $\begin{array}{l}\text { Weight } \\
(\mathrm{g})\end{array}$ & $\begin{array}{l}\text { Density } \\
\left(\mathrm{g} / \mathrm{cm}^{3}\right)\end{array}$ \\
\hline A & 98 & 2 & \multirow{4}{*}{30} & \multirow{4}{*}{3.5} & 35.0 & 9.9 \\
\hline B & 96 & 4 & & & 29.0 & 8.2 \\
\hline C & 92 & 8 & & & 26.0 & 7.4 \\
\hline \multirow[t]{2}{*}{ D } & 90 & 10 & & & 20.0 & 5.7 \\
\hline & \multicolumn{2}{|c|}{$\begin{array}{l}\text { Polyester:WH: } \\
\text { catalyst }\end{array}$} & $\begin{array}{l}\text { Diameter } \\
(\mathrm{mm})\end{array}$ & $\begin{array}{l}\text { Volume } \\
\left(\mathrm{cm}^{3}\right)\end{array}$ & $\begin{array}{l}\text { Weight } \\
\text { (g) }\end{array}$ & $\begin{array}{l}\text { Density } \\
\left(\mathrm{g} / \mathrm{cm}^{3}\right)\end{array}$ \\
\hline E & \multirow{2}{*}{\multicolumn{2}{|c|}{$\begin{array}{c}200 \mathrm{ml}: 25 \mathrm{~g}: \\
20 \mathrm{ml}\end{array}$}} & 30 & 9.9 & 12.0 & 1.2 \\
\hline $\mathrm{F}$ & & & 30 & 19.8 & 23.5 & 1.2 \\
\hline G & \multirow{2}{*}{\multicolumn{2}{|c|}{$\begin{array}{l}200 \mathrm{ml}: 25 \mathrm{~g}: \\
\quad 20 \mathrm{ml}\end{array}$}} & 30 & 10.6 & 10.0 & 1.0 \\
\hline $\mathrm{H}$ & & & 30 & 21.2 & 19.0 & 0.9 \\
\hline
\end{tabular}

WH: water hyacinth; polyester used is JUSTUS 2522

A-D are the WH based ceramics; $\mathrm{E}$ and $\mathrm{F}$ are the $\mathrm{WH}$ composites, and $\mathrm{G}$ and $\mathrm{H}$ are the Coco-husk composites

Table 1 shows that the five porous ceramic and $\mathrm{WH}$ fiber composite samples were measured on their densities. The results indicate that the less the content of WH fiber in the ceramic, the more the density of the materials (see samples A-D). Unlike the ceramics, the natural fiber composite (E) seems to have a density that is quite low compared to the density of ceramic specimens. However, they have distinguished on their void and solid performances. Although the ceramics had quite high density, they have a cavity on each sample, which makes the sound trapped on it. On the other hand, the composite has less density mass, which may absorb the sound energy optimally. 


\subsection{Sound Absorption Coefficient}

The ASTM E1050-98 (DK-2850, Naerum, Denmark) was used to observe the normal incidence sound absorption coefficients of materials[12]. This method used $30 \mathrm{~mm}$ B\&K impedance tubes, 4206 series equipped with two microphones location and system called digital frequency analyzer. The one end of the impedance tube was connected to the sound source, while the material specimen was fitted at another end of the tube. A sound source, which emits a broadband signal, is used to generate a plane wave into the $\mathrm{B} \& \mathrm{~K}$ tube. This method may obtain the data faster than the previous procedure of ASTM C 384 because the frequency range could be adjusted by managing the distance between the microphone and the specimen within the impedance tube. Therefore, the range of frequencies determines the quantity of sound absorption coefficient that could be obtained from the digital system of a frequency analyzer. This method is used to measure the sound absorption performance obtained from the normal incidence of the sound source that is installed at one end of the tube with the sample material at the other end. Impedance tubes must be completely clean so there is no attenuation of sound at low frequencies and unnecessary sound transmission to the tube walls. The formula used in this method is response function, $\mathrm{H}_{1,2}$, as results of sound decomposition and sound reflection $\mathrm{R}$ :

$$
\begin{gathered}
H_{1,2}=\frac{P_{1}}{P_{2}}=\frac{e^{j k h}+e^{-j k h}}{e^{j k(h+s)}+e^{-j k(h+s)}} \\
R=\frac{H_{1,2}-e^{j k s}}{e^{j k s}-H_{1,2}} e^{j 2 k(h+s)} \\
\alpha=1-[R]^{2}
\end{gathered}
$$

The sound pressure levels were captured by two microphones, $P_{I}$ and $P_{2} ; k$ is the wavenumber; $h$ and $j$ are the distance between the sample and the first and the second microphones respectively; $s$ is the distance between two microphones (see equations 1 and 2) and $\alpha$ is the absorption coefficient (see Eq. 3).

\subsection{Sound Transmission Loss}

The ASTM E2611-09 method is a new method of measuring the normal incidence sound transmission performance of a sample material using the transfer matrix method[13]. The new ASTM E2611-09 method is similar to ASTM E1050-98 where the sound source is installed at one end of the tube and the material sample is attached to the other end of the tube. The difference is the number of microphones attached to the tube. Unlike the ASTM E1050-98, this method uses four microphones, the B\&K 4187 series, which capture standing waves propagating within the tube. The plane wave and broadband signal emitted from the sound source propagates inside the tube and further, at each frequency, the resulting standing wave pattern is decomposed into a forward and backward motion component by measuring sound pressure simultaneously at four microphones to check its relative amplitude and phase. The acoustic transfer matrix is calculated from the pressure and velocity of the wave particles by evaluating the difference in sound strength between the two sides of the specimen.

Figures 2 shows the impedance tube section with four microphones located at a certain distance to the sample in the middle of the tube to measure the Sound Transmission Loss performance of the specimen.

$$
S T L=20 \log \left|\frac{e^{j k s}-H_{1,2}}{e^{j k s}-H_{3,4}}\right|-20 \log \sqrt{\left|S_{d} / S_{u}\right|}
$$

Where $H_{1,2}$ represents the transfer function at position 1 and 2 , while $H_{3,4}$ is the quantity of transfer function at position 3 and 4 . Further, the $S_{d} / S_{u}$ is the ratio of the auto spectrum in both the upper and lower tubes.

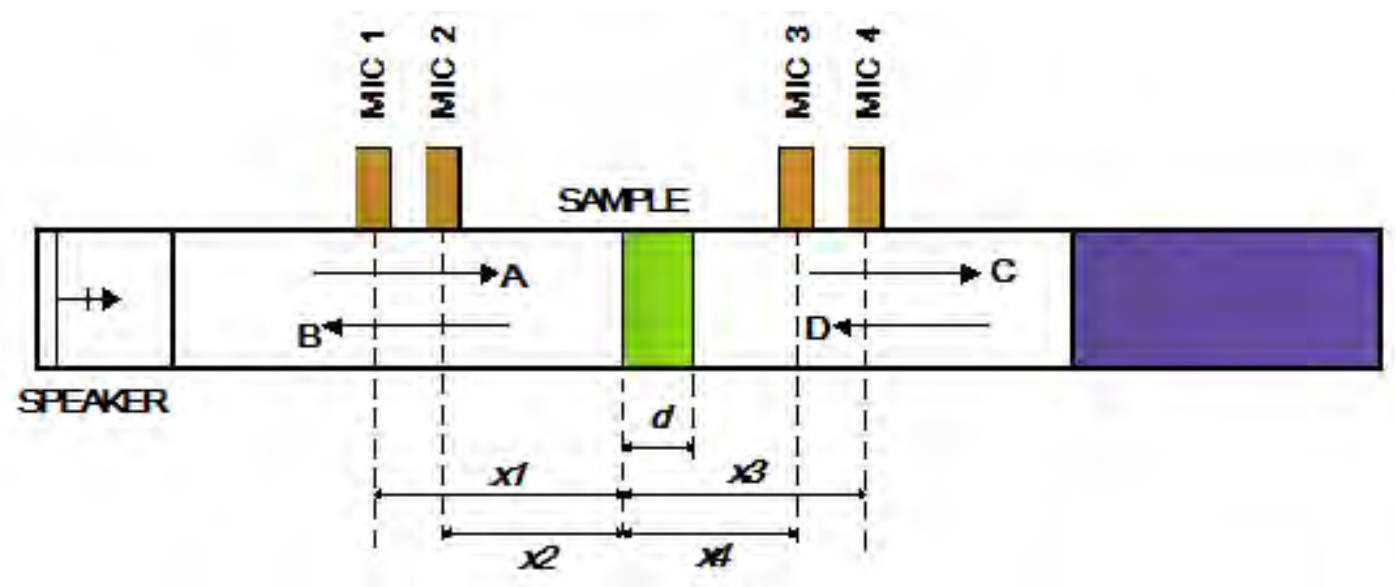

Figure 2. Measurement method with four microphones of ASTM E2611-09 


\section{Results and Discussion}

\subsection{Sound Absorption Coefficient}

Setyowati et al. concluded that the natural fibers in the composite are the potential to be implemented in architectural acoustics due to their specifications on reducing the sound energy absorption in certain frequencies[1], [2]. Figure 3 describes the performance of sound absorption of materials, which principally occur as the poor absorber. Indeed, it shows that the Helmholtz performance of ceramic is better than the composites. The results then were analyzed statistically based on the Anova method. The significance of the data was shown in Table 2 below, while the rank of the sound absorption performance was indicated in the next figures as the table of homogeneous subsets and the means plot graph respectively.

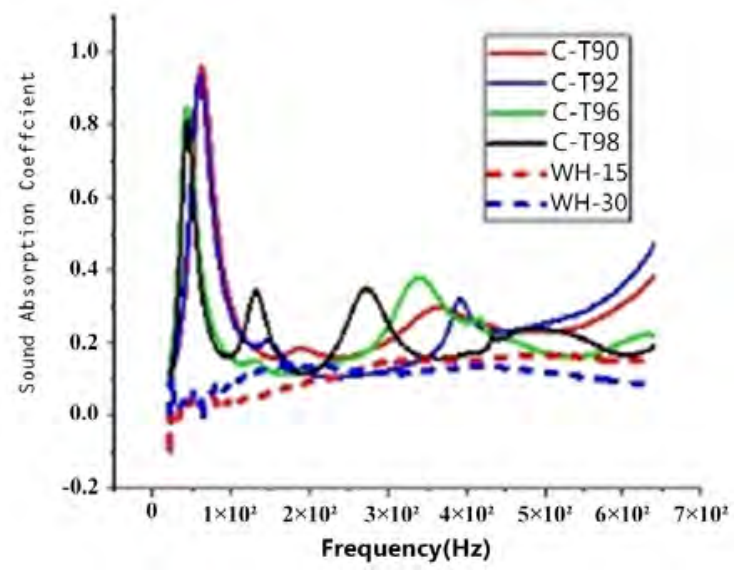

Figure 3. The comparison of the absorption coefficient of materials

Figure 3 reveals that the ceramics with WH contents of $8 \mathrm{wt} \%$ and $10 \mathrm{wt} \%$ (see the line red and blue in Fig. 3) had their peaks of $0.9-1.0$ at $8 \mathrm{ks}-9 \mathrm{ks}$ Hertz. The poor performances occurred on the Water Hyacinth based composites with 15 and $30 \mathrm{~mm}$ thickness which had less than 0.20 . The performance rank can be seen in Table 3 and Figure 4 below.

Table 2. ANOVA of Sound Absorption Performance

\begin{tabular}{|c|c|c|c|c|c|}
\hline & $\begin{array}{c}\text { Sum of } \\
\text { Squares }\end{array}$ & df & $\begin{array}{c}\text { Mean } \\
\text { Square }\end{array}$ & F & Sig. \\
\hline $\begin{array}{c}\text { Between } \\
\text { Groups }\end{array}$ & 18.2 & 5 & 3.6 & 300.9 & 0.0 \\
\hline $\begin{array}{c}\text { Within } \\
\text { Groups }\end{array}$ & 56.1 & 4,650 & 0.0 & & \\
\hline Total & 74.3 & 4,655 & & & \\
\hline
\end{tabular}

Table 2 indicates that the data reach a significance of 0.0 . The comparison of materials can be continued to the next table and figure.
Table 3. Homogeneous Subsets of Sound Absorption

\begin{tabular}{|c|c|c|c|c|c|}
\hline \multirow{4}{*}{} & \multirow{2}{*}{ Material } & \multirow{2}{*}{$\mathrm{N}$} & \multicolumn{3}{|c|}{ Subset for alpha $=0.05$} \\
\cline { 4 - 6 } & & & 1 & 2 & 3 \\
\hline \multirow{5}{*}{ Tukey HSD } & WH-30 & 776 & 0.1 & & \\
\cline { 2 - 6 } & WH-15 & 776 & 0.1 & & \\
\cline { 2 - 6 } & C-T98 & 776 & & 0.2 & \\
\cline { 2 - 6 } & C-T96 & 776 & & 0.2 & \\
\cline { 2 - 6 } & C-T92 & 776 & & & 0.3 \\
\cline { 2 - 6 } & C-T90 & 776 & & & 0.3 \\
\hline & Sig. & & 0.7 & 1.0 & 0.1 \\
\hline
\end{tabular}

Means for groups in homogeneous subsets are displayed

a. Uses Harmonic Mean Sample Size $=776.0$

Table 3 reveals that the ranking order follows a logical order in which the C-T90 and C-T92 are in a group with an average sound absorption of 0.3 . Also in a logical order, that the C-T96 and C-T98 have average sound absorption of 0.2 .

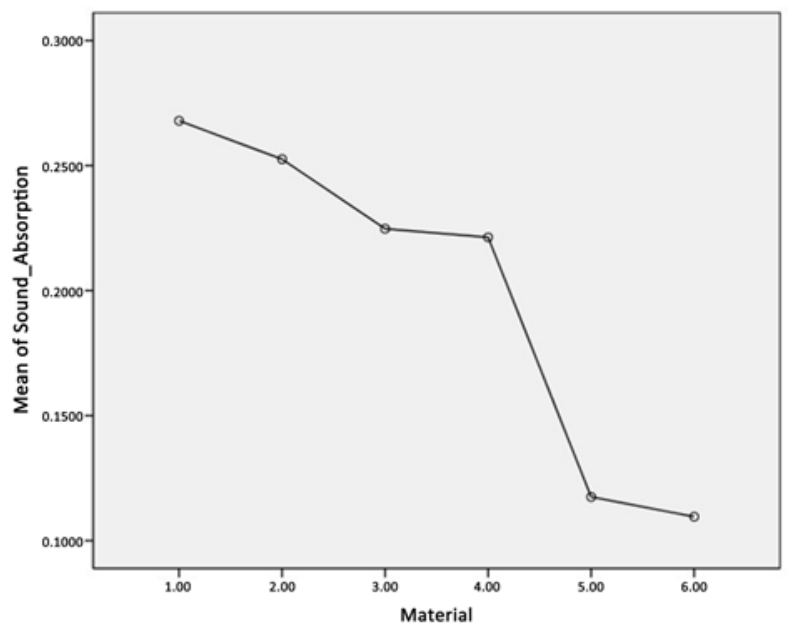

Figure 4. Means plot of sound absorption performance

Meanwhile, the water hyacinth based composites of WH-15 and WH-30 have the lowest average sound absorption. Although the density of ceramic is higher than composite, the concept of Helmholtz with resonators and cavities in ceramics makes this material very good in absorbing sound performance.

The absorption performance rank is also described in Figure 4. The understanding that density affects the acoustical behavior of the material can be expressed here. However, the concept of Helmholtz resonator, which is owned by porous ceramics, makes this material very good at absorbing sound. Setyowati's study compared water hyacinth and coco-husk composite, which revealed that the abilities of the two can be compared as biomass fiber content[1]. Then, the new coco-husk composite will experience an advantage if it is given an additional air gap and a fibrous layer. However, in this study, the ability of hexagonal ceramics far outperformed the ability of water hyacinth composite in terms of sound absorption. The sequence illustrated in Table 3 and described in Figure 4 
occurs based on a logical sequence, in which porous ceramics with more water hyacinth content will have a higher absorption power. Meanwhile, for water hyacinth based composites, it appears that the lower the density, the greater the absorption coefficient. If the results are compared to another natural fiber-based composite in previous research, then a coco-husk based composite that has good acoustic performance is the right choice. Figure 5 describes comparatively between water hyacinth ceramic and both water hyacinth and coco-husk composites.

The statistical results of average sound absorption of WH-based ceramic and composite, as well as coco-husk composite, were indicated that the highest absorption value occurred on $15 \mathrm{~mm}$ thickness water hyacinth composite with additional 8 resonators which reach the peak of 0.9 at $3.5 \mathrm{k} \mathrm{Hz}$ (see Figure 5).

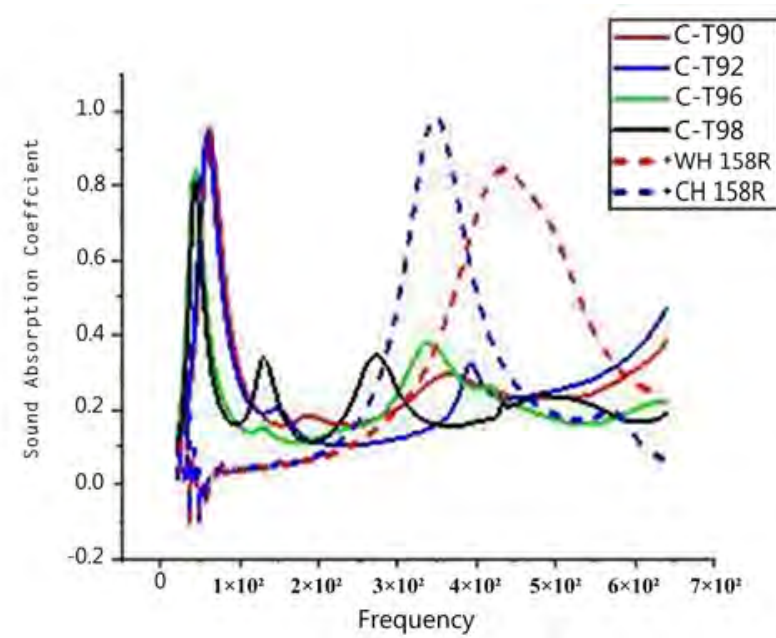

Figure 5. The absorption of WH based ceramic and composite compared to water hyacinth and coco-husk composite with 8 resonator

The WH $15 \mathrm{~mm}$ with 8 resonators also has the highest average sound absorption compared to others (see the blue and red short-dash lines). The $15 \mathrm{~mm}$ coco-husk with 8 resonators has not shown its advantages, although, in initial research, it had the best rank with an additional 10 $\mathrm{mm}$ air gap which showed wideband frequencies ability[1].

\subsection{Sound Transmission Loss}

The most natural fibers in the composite are the potential on reducing the sound energy in certain frequencies, but they mostly had less insulation performance, because of their less mechanical properties. The composites which hot pressing processed have been brittle, flammable, and easily moldy, while the composites made with a mixture of synthetic fibers and processed with normal temperature hardening have better durability but poor absorption. If acoustic treatment is not carried out, the latter type will still have low absorption power. The normally hardened composites are also better in insulation performance than the hot-pressed ones. In the current research, sound transmission loss behavior has also been investigated. Refer to the ASTM E2611-09, the sample of materials has been observed by the B\&Ks' impedance tube equipped with four microphones. The results are presented in Figures 6 and 7 below.

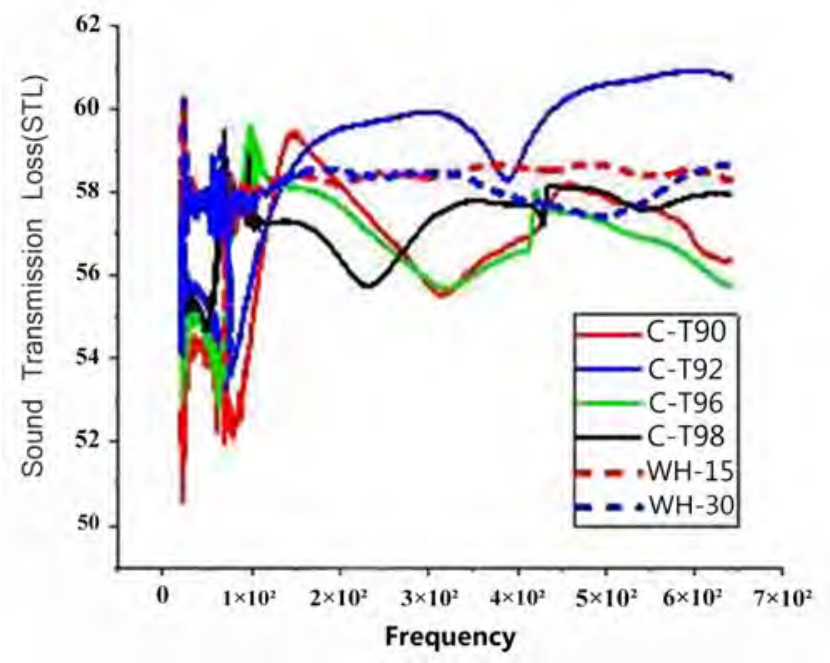

Figure 6. The Sound Transmission Loss of materials

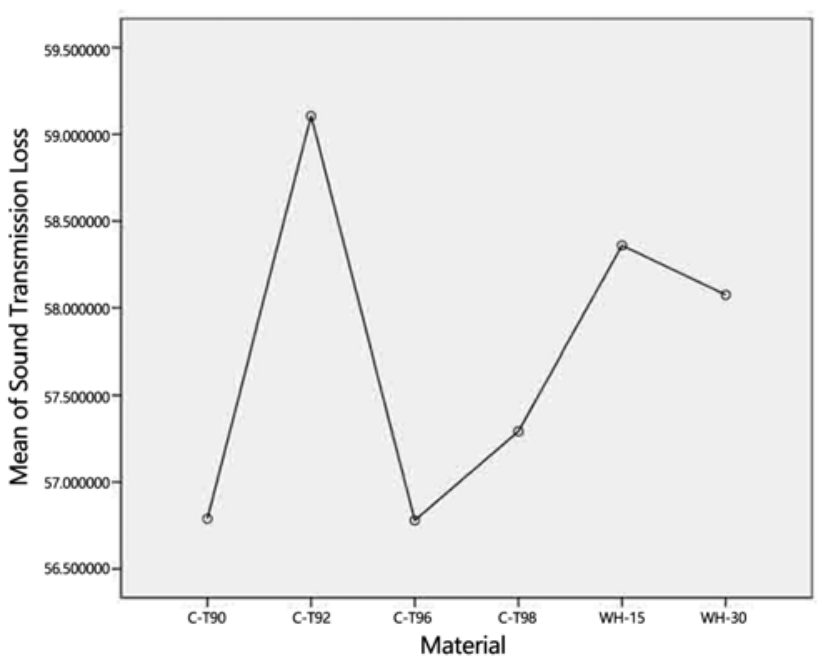

Figure 7. Means plot graph

Figure 6 shows that porous ceramics with 8 wt $\%$ water hyacinth have noise-canceling power in wideband frequencies (see the blue line in Figure 6). This differs from the C-T90, C-T96, and C-T98 porous ceramics, which contain water hyacinth, as much as $10 \mathrm{wt} \%, 4 \mathrm{wt} \%$, and $2 \mathrm{wt} \%$ respectively. While The Means plot graph in Figure 7 shows that ceramic with a composition of $8 \mathrm{wt} \%$ water hyacinth has the best average Sound Transmission Loss of all. However, the second-best goes to the water hyacinth composite with $15 \mathrm{~mm}$ thickness with $58.4 \mathrm{~dB}$.

Table 4 shows that there are significant differences between material groups (see column Significance). Therefore, it can be concluded that the six groups of specimens can be compared with each other. Then, to determine the ranking position of the six materials, the 
Homogeneous subsets test was then performed.

Table 4. ANOVA of Sound Transmission Loss

\begin{tabular}{|c|c|c|c|c|c|}
\hline & $\begin{array}{c}\text { Sum of } \\
\text { Squares }\end{array}$ & df & $\begin{array}{c}\text { Mean } \\
\text { Square }\end{array}$ & F & Sig. \\
\hline $\begin{array}{c}\text { Between } \\
\text { Groups }\end{array}$ & 13605.5 & 5 & 2721.1 & 2055.6 & 0.0 \\
\hline $\begin{array}{c}\text { Within } \\
\text { Groups }\end{array}$ & 24621.7 & 18,600 & 1.3 & & \\
\hline Total & 38227.2 & 18,605 & & & \\
\hline
\end{tabular}

In Table 5, it is known that the highest-ranking value for Sound Transmission Loss occurs at C-T92 (ceramic with $8 \mathrm{wt} \%$ water hyacinth) with an average value of Sound Transmission Loss of $59.1 \mathrm{~dB}$, while the second rank is water hyacinth composite with $15 \mathrm{~mm}$ thickness, which has an average value of $58.4 \mathrm{~dB}$. Furthermore, for the ceramic with $10 \mathrm{wt} \%, 4 \mathrm{wt} \%$, and $2 \mathrm{wt} \%$ are on fifth, sixth, and fourth ranks, with average values of Sound Transmission Loss of 56.8, 56.8, and 57.3 dB respectively. The means plot graph can be seen in Figure 7.

\subsection{Water Hyacinth Based Composite and Ceramic Application in Architecture}

Table 5. Homogeneous Subsets of Sound Transmission Loss

\begin{tabular}{|c|c|c|c|c|c|c|c|}
\hline \multirow{4}{*}{} & \multirow{2}{*}{ Material } & \multirow{2}{*}{$\mathrm{N}$} & \multicolumn{5}{|c|}{ Subset for alpha=0.05 } \\
\cline { 4 - 8 } & & & 1 & 2 & 3 & 4 & 5 \\
\hline \multirow{5}{*}{ Tukey HSD } & C-T96 & 3101 & 56.8 & & & & \\
\cline { 2 - 8 } & C-T90 & 3101 & 56.8 & & & & \\
\cline { 2 - 8 } & C-T98 & 3101 & & 57.3 & & & \\
\cline { 2 - 8 } & WH-30 & 3101 & & & 58.1 & & \\
\cline { 2 - 8 } & WH-15 & 3101 & & & & 58.4 & \\
\cline { 2 - 8 } & C-T92 & 3101 & & & & & 59.1 \\
\cline { 2 - 8 } & Sig. & & 1.0 & 1.0 & 1.0 & 1.0 & 1.0 \\
\hline
\end{tabular}

Means for groups in homogeneous subsets are displayed

a. Uses Harmonic Mean Sample Size $=3101.000$
Many decades ago, natural fiber composite has taken an important role in architectural material which has various implementations in building especially as acoustical elements in the interior.

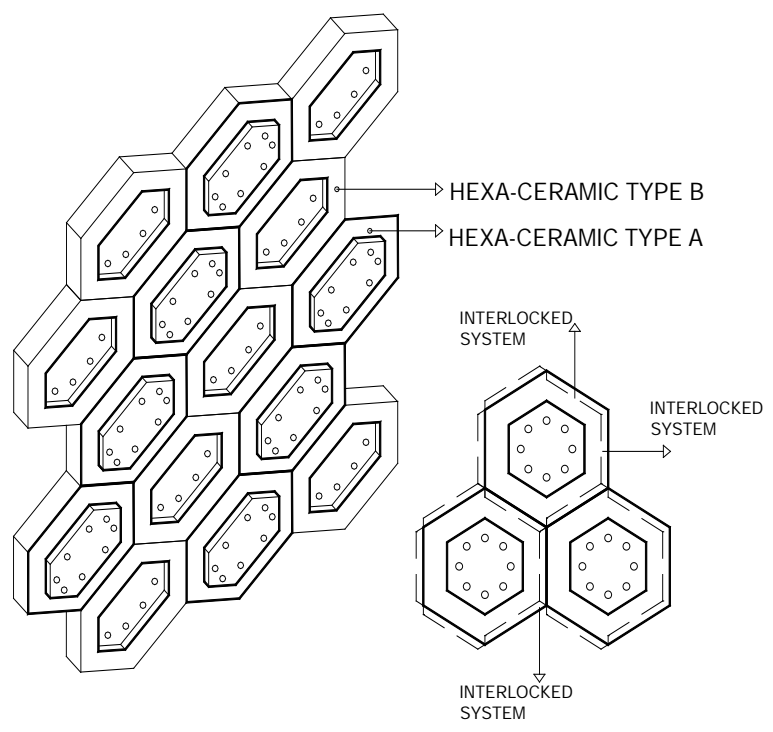

Figure 8. Hexa-ceramic application in Architecture 


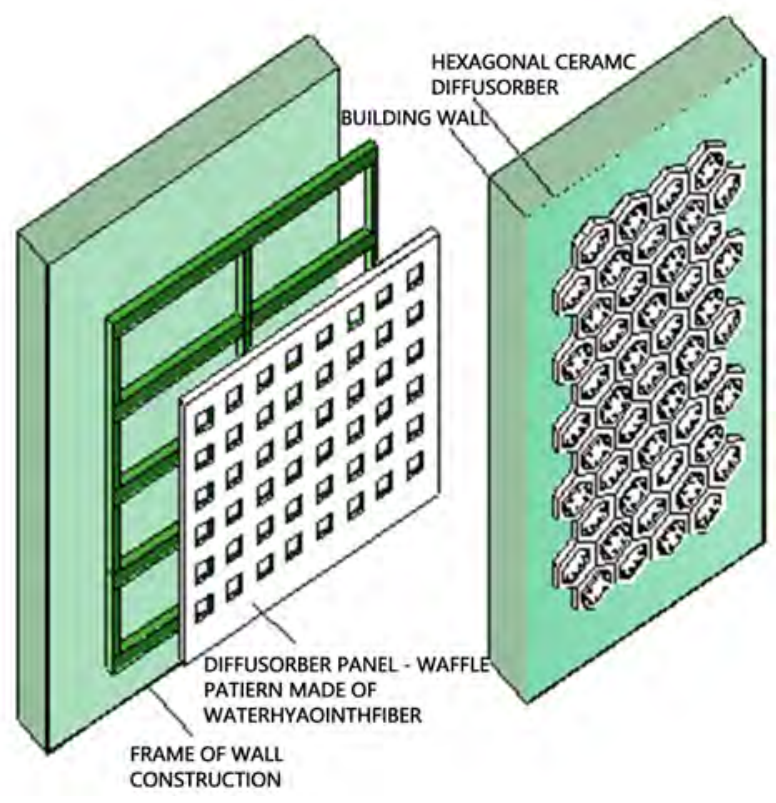

Figure 9. The applications of water hyacinth based ceramic and composites in Architectural interior

The Hexa-ceramic has two type elements covering types A and B (see Figure 8). Type A has a protrusion 2 $\mathrm{cm}$ thick or $1 / 3$ the thickness of the Hexa ceramic. Meanwhile, type B has a basin with the same depth as the protrusion of type A. The type A and type B mounting arrangements alternate so that they form regular protrusions and hollows in the ceramic pattern attached to the wall. The protrusions and depressions serve to absorb and diffuse sound energy. Thus, the material not only functions as a sound absorber but also diffuses the sound or is known as a sound diffuser-absorber. Meanwhile, the inside of the ceramics forms a Helmholtz space, which is quite wide and able to pick up incoming sound and muffle and imprison the sound inside the ceramic. With this sound trapping mechanism, the sound can be well absorbed by the hexagonal ceramic. Figure 9 shows the application of hexagonal ceramic and composite to the interior wall of a building. Unlike the hexagonal ceramic, which can be fitted on the wall straightly with mortar, the water hyacinth-based composite needs a frame to be installed on the wall; afterward, the composite could be installed next to the frame (see Figure 9).

In the application in building, the resonance of the Hexagonal porous ceramic wall has been measured by Reverberation Time. As Reverberation time is a time needed for the sound energy to decay as much as $60 \mathrm{~dB}$, the measurement has been conducted with Reverberation Time application on the distance of 1.0 meter in front of the hexagonal ceramic which is installed in the building. The building type using the hexagonal is a conventional building in the center of the campus zone in Semarang, Indonesia. The Reverberation Time application recorded the resonance of the sound energy and the results of resonance are described as the graph in Figure 10.

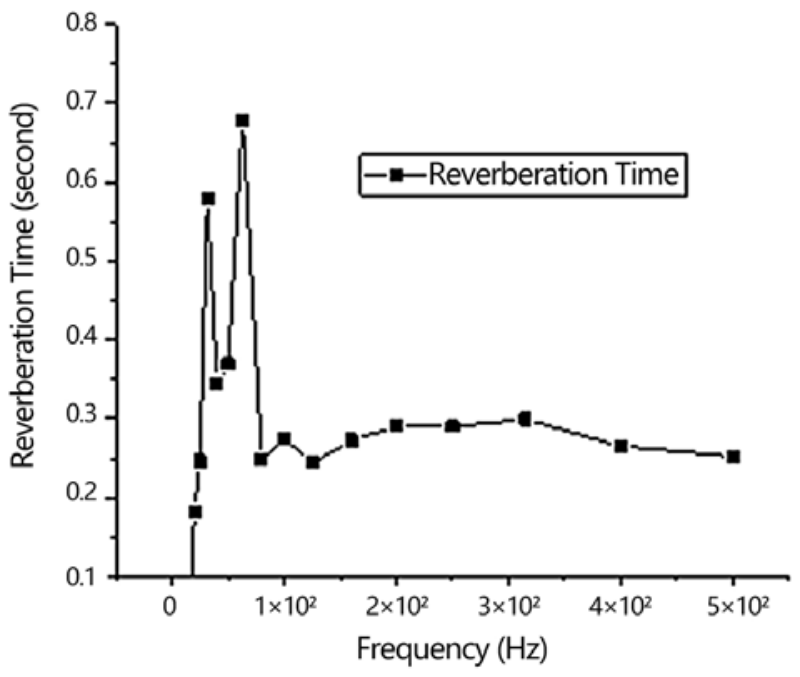

Figure 10. Resonance performance of Hexagonal Porous Ceramic

Figure 10 illustrates the resonance performance of Hexagonal porous ceramic. The hexagonal has high resonance in frequencies of $300 \mathrm{~s}$ and $600 \mathrm{~s} \mathrm{~Hz}$, while in other frequencies, the performance is quite good. The high resonance occurs due to the geometrical shape and chamber conditions such as temperature, humidity as well as electro-acoustic owned by the building. The average reverberation time is 0.29 seconds. Several studies have discussed Helmholtz resonators as well as their influence on sound absorption and sound transmission loss (STL). Research conducted by Brandao and Schnitzer[14] created modeling about the acoustic performance of the Helmholtz resonator. The geometrical Helmholtz has been created with various long dimensions of the Helmholtz resonator neck. Another research demonstrated and established a robust method for estimating and measuring the acoustic metamaterial properties of a Helmholtz researcher in analytical, numerical, and experimental details[15]. The proposed numerical technique simulated the ASTM-2611 measurement standard to extract the corresponding reflection and transmission coefficients to evaluate the properties of the effective acoustic metamaterial[15].

Helmholtz resonator innovation without using thick panels has been done. The experiment used a small tube as Helmholtz resonator's neck and a large tube functioned as a resonance chamber. By using 3D printing technology, geometry manipulation could be done to investigate the peak of sound absorption[16]. The research on Helmholtz aims to achieve narrowband performance in the field of acoustics. The next research on the Helmholtz resonator was an improvement in sound transmission capability on double walls[17]. The study highlighted the increased treatment of sound transmission on double walls by performing acoustic Vibro arrangements between double walls with conditions beyond double walls. A new analytical model using effective material parameters has been developed[17]. 


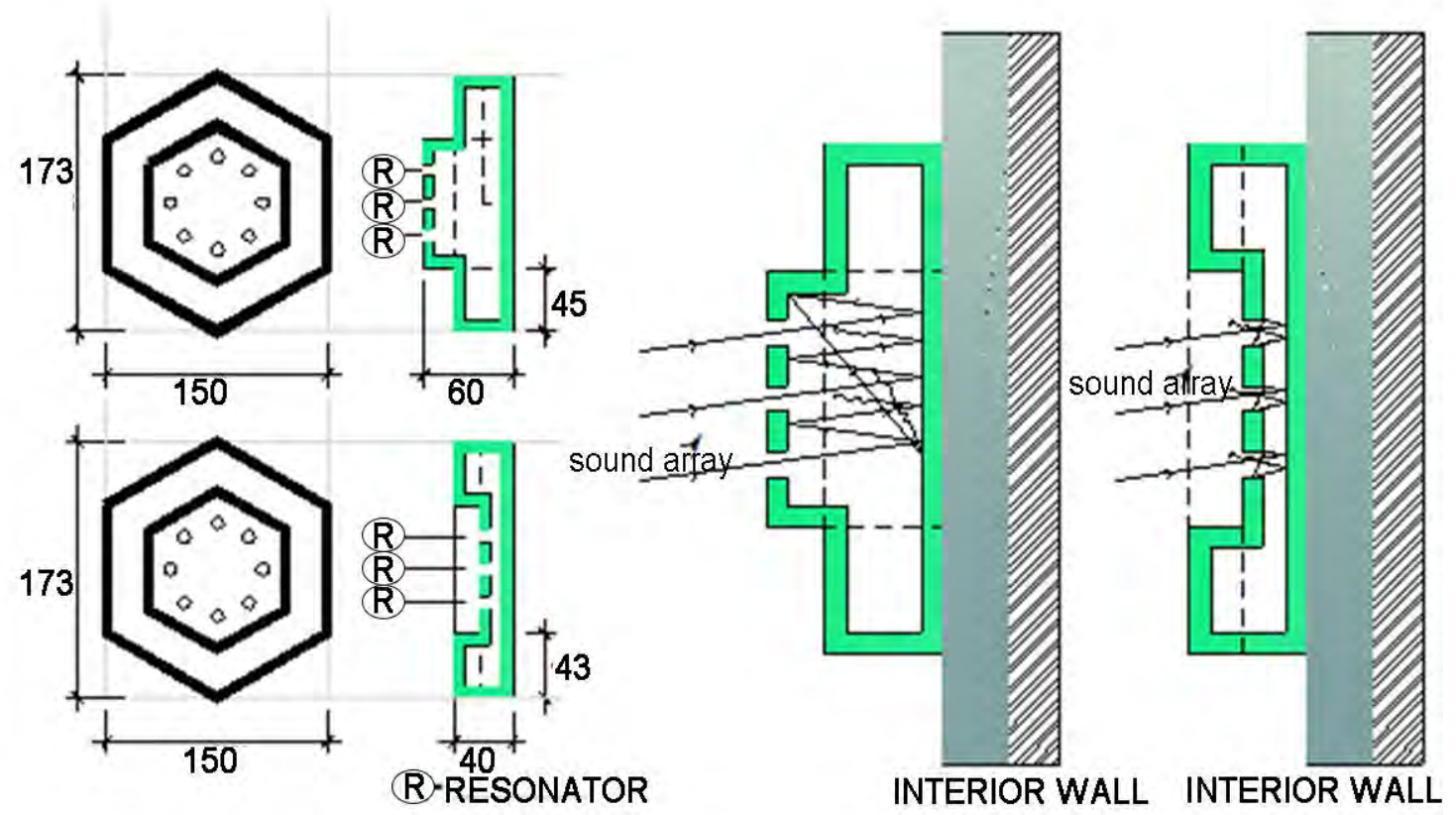

(a)

(b)

Figure 11. (a) Hexa-ceramic section and (b) sound array enter the Helmholtz space

On the other hand, research conducted by Selamet and Lee has successfully extended the construction neck of the Helmholtz resonator[18]. The extension of the Helmholtz resonator neck was theoretically, numerically, and experimentally investigated. The effect of length and shape, and perforation on neck extensions were examined at the resonance frequency and transmission loss. A two-dimensional analysis method was developed for an extended neck with a constant cross-section area, while a three-dimensional boundary element method was applied to variable areas and perforated extensions[18]. Furthermore, research on mathematical modeling and physics has been developed by Ammari and Imeri[19]. This paper deals with mathematical models to calculate the amount of scattering through the narrow gaps of the Helmholtz resonator mounted on a surface.

Besides, this study showed that at a certain length for certain openings and frequencies there was a sudden shift of the dispersed wave phase due to the resonance of Helmholtz resonator subwavelength. A numerically fast implementation was given to identify the region of the aperture specific values and the frequency [19]. The sound array enters the Helmholtz space with a certain angle as the angle comes. After hitting the Helmholtz surface on the inside then the sound will be reflected, insulated by a ceramic wall, or absorbed and imprisoned in the Helmholtz space of hexagonal ceramic (see Figure 11).

\section{Conclusions}

Water hyacinth plays an important role in developing interesting studies for many researchers all around the world, especially for the countries where this plant fills up the swamp areas. Because the plant takes some nutritious contents and oxygen from the swamp, sedimentation occurs in the swamp area and this sporadic and fast-growing plant threatens the biodiversity. A lot of studies have been developed by a huge number of researchers associated with the innovation of sound absorber materials. Many materials made of natural fibers have been flammable, weak in mechanical properties, and lacked durability. Accordingly, the current research has an idea to make such kind of materials, which are tough in their nature but have acoustical performances that need to be considered for architecture applications. In current research, acoustical performances between water hyacinth based ceramic and other composite were compared. Besides, the results are that all the ceramic material has gained good values of sound absorption coefficient over those of the composites' absorption performance at $0.25-$ 0.27 . It occurs because the concept of the Helmholtz resonator is owned by the WH ceramics which have a good ability to trap the sound although, in nature, this material is tough and reflective. Furthermore, the additional water hyacinth in the clay mixture makes the sound energy easily to be absorbed by the surface of unfurnished-porous ceramics. The eight resonators in each ceramic tile make the sound possible to enter the Helmholtz space within the ceramic. Meanwhile, in terms of insulation, ceramic with water hyacinth fiber of $8 \mathrm{wt} \%$ (C-T92) shows its superiority with a value of STL of 59.1 $\mathrm{dB}$. The next best-insulated material was composite water hyacinths 15 and 30 thicknesses with STL values of 58.3 
and 58.1, respectively. In terms of resonance performance, the Reverberation Time method was used to observe the time needed by the sound energy to decay as much as $60 \mathrm{~dB}$. The result shows that the resonance performance is quite good with an average of 0.29 seconds. This study has several drawbacks where the level of porosity of the material has not been well observed. This leads to the effort of further research, which could make more detailed observations related to the level of material porosity.

\section{Nomenclatures}

\begin{tabular}{|l|l|}
\hline ASTM: & American Standard Testing and Material \\
\hline$\alpha:$ & Sound absorption coefficient \\
\hline WH: & Water hyacinth \\
\hline STL: & Sound Transmission Loss \\
\hline B \& K: & $\begin{array}{l}\text { Bruer \& Kjaer, manufacture name of the Impedance } \\
\text { Tube to measure and observe the acoustical behavior } \\
\text { of the material }\end{array}$ \\
\hline H: & Number of quarter wavelength resonators \\
\hline C: & Cavity (10 mm) \\
\hline EDX: & Energy Dispersive Spectroscopy (EDS) oxide \\
\hline ZAF: & $\begin{array}{l}\text { Matrix effect in EDS oxide, related to all elements } \\
\text { presents in the sample and in the standard covering } \\
\text { Production or the symbol of atomic number (Z), } \\
\text { Absorption (A) and enhancement of the characteristic } \\
\text { radiation (F) or fluorescence that must be taken into } \\
\text { account. }\end{array}$ \\
\hline
\end{tabular}

\section{Acknowledgments}

Our gratitude is addressed to the Research Centre of Universitas Diponegoro that makes this study possible to be granted by the Ministry. This research has been funded by the Ministry of Education and Culture, the Republic of Indonesia number 225-118/UN7.6.1/PP/2020 and High Reputation Internasional Publication research grant number 329-120/UN7.6.1/PP/2020. The last thank goes to the Iwany Research Group, Universitas Sebelas Maret, Surakarta that collaborates with the team for the observations of the materials on their acoustical performances.

\section{Conflicts of Interest}

We declare that there is no Conflict of Interest in this research.

\section{REFERENCES}


configurations of Helmholtz resonators," Appl. Acoust., vol. 155, pp. 371-382, 2019.

[16] J. Chen, Y. Chen, Y. Cheng, and L. Chou, "A sound absorption panel containing coiled Helmholtz resonators," Phys. Lett. A, vol. 384, no. 35, p. 126887, 2020.

[17] F. Langfeldt, H. Hoppen, and W. Gleine, "Broadband low-frequency sound transmission loss improvement of double walls with Helmholtz resonators," J. Sound Vib., vol.
476,2020

[18] A. Selamet and I. Lee, "Helmholtz resonator with extended neck a )," J. Acoust. Soc. Am., vol. 113, no. 4, pp. 1975-1985, 2014.

[19] H. Ammari and K. Imeri, "A mathematical and numerical framework for gradient meta-surfaces built upon periodically repeating arrays of Helmholtz resonators," Wave Motion, vol. 97, p. 102614, 2020. 